\title{
IMPLEMENTASI NILAI-NILAI DAKWAH SANTRI MELALUI PERIBAHASA ARAB MAHFUDZAT
}

(Tinjauan Sosiolinguistik, Studi Atas Buku Al-Mahfudzat Kelas IX MTs Pondok Pesantren Modern Al-Junaidiyah Biru Bone Karya KM. Syarifuddin Husain)

\author{
A. Fajar Awaluddin \\ Program Studi Ilmu Al-Qur'an dan Tafsir IAIN Bone \\ Email : fajarcece@gmail.com.
}

\begin{abstract}
Da'wah activities in a plurality society not only have a strong basic principles of faith but can also realize basic principles of moral and social ethics. Their existence must receive guidance so that the community has the character of loving kindness, opposing evil, and not recognizing violence in accordance with Islamic teachings. Under these conditions, a strong foundation of faith will be able to realize a life that is in harmony with everyday life such as a sense of social justice, security, mutual assistance to help, respect, and others. The values of da'wah mentioned above must be implemented in everyday life in a plurality society with reference to the principles, namely : (1) Islamic civilization stand son the basis of monotheism,(2) civilization that is humane, transcendental, and has international insight, (3) always hold moral principles.
\end{abstract}

Keywords: The values of da'wah, Proverb, Mahfudzat

\begin{abstract}
Abstrak
Kegiatan dakwah pada masyarakat pluralitas bukan saja sekedar memiliki prinsip dasar keimanan yang kuat tetapi juga dapat mewujudkan prinsip dasar moral dan etika sosial. Keberadaan mereka harus mendapatkan pembinaan agar masyarakat memiliki karakter mencintai kebaikan, menentang keburukan, dan tidak mengenal kekerasan sesuai dengan ajaran Islam. Dalam kondisi semacam ini dasar keimanan yang kuat akan dapat mewujudkan kehidupan yang selaras dengan kehidupan sehari-hari seperti rasa keadilan sosial, keamanan, saling tolong menolong, menghormati, dan lainnya. Dalam kajian sosiolinguistik peribahasa Arab dalah buku Mahfudzat kelas IX MTs terdapat tiga kajian yaitu standar,otonomi, dan historisitas.. Nilai-nilai dakwah yang universal mengatur hubungan yang didasarkan pada aspek saling menghormati, tidak memaksa, azas keadilan, kemanusiaan, kebersamaan.
\end{abstract}

Kata Kunci : Nilai-Nilai Dakwah, Peribahasa, Mahfudzat

\section{PENDAHULUAN}


Peribahasa adalah kelompok kata atau kalimat yang menyatakan suatu maksud, keadaan seseorang, atau hal yang mengungkapkan kelakuan, perbuatan atau hal mengenai diri seseorang. Peribahasa mencakup ungkapan, pepatah, perumpamaan, ibarat, tamsil. (Kamus Umum Bahasa Indonesia susunan BaduduZain (1994). Pada umumnya, kelompok kata atau kalimat dalam peribahasa memiliki struktur susunan yang tetap, dan merupakan kiasan terhadap suatu maksud. Kalimat yang dipakai biasanya mengesankan dan memiliki arti yang luas. Didalam suatu peribahasa terdapat unsur sistem budaya masyarakat yang berhubungan dengan nilai-nilai, pandangan hidup, norma dan suatu aturan dalam masyarakat. Pada kebudayaan Melayu peribahasa sering dipakai atau diucapkan dalam kehidupan sehari-hari, dengan kata lain sastra lisan ini merupakan salah satu sarana enkulturasi dalam proses penanaman nilai-nilai adat dari waktu ke waktu.

Pendidikan dipandang sebagai aspek yang berperan dalam membentuk generasi mendatang, melalui pendidikan di pesantren diharapkan dapat menghasilkan santri yang berkualitas dan bertanggung jawab serta mampu mengantisipasi masa depan. Oleh karena itu, diperlukan pembenahan dan perbaikan kualitas pendidikan di pesantren untuk mencapai peningkatan kualitas sumber daya manusia.

Pondok pesantren sangat berperan penting dalam meningkatkan kualitas sumber daya manusia dalam memahami dan mendalami agama Islam itu sendiri. Pondok pesantren menjadi salah satu sarana yang sangat efektif dalam mengatasi masalah tersebut.Kehadiran pondok pesantren pada awalnya tidak hanya sebagai lembaga pendidikan saja, tetapi sebagai lembaga penyiaran agama Islam. Pondok pesantren mempunyai kelebihan dibandingkan dengan lembaga pendidikan formal lainnya, karena pondok pesantren merupakan satusatunya lembaga pendidikan di Indonesia untuk tadaqquh fiddien, yaitu memahami manusia dalam urusan agama.

Dalam memberikan pemahaman manusia dalam urusan agama, pesantren memiliki kepedulian dalam membina para santri untuk memberikan manajemen pelatihan dalam berdakwah. Manajemen pelatihan bagi para santri Pondok 
Pesantren Modern Al-Junaidiyah Biru ini diberikan sebagai salah satu program dalam lembaga pendidikan tersebut untuk memberikan kontribusi kepada masyarakat dalam memajukan dunia pendidikan melalui dakwah. Dengan program ini, maka akan meningkatkan kualitas dakwah bagi para santri yang akan berdakwah kepada masyarakat.

Berdakwah merupakan kegiatan yang menyeru kepada kebaikan dan mencegah dari yang mungkar yang dilakukan oleh dai kepada mad'u untuk mencapai kemaslahatan dan kebahagiaan di dunia dan di akhirat. Dalam menjalankan kegiatan dakwah yang terfokus pada pemurnian aqidah bukan saja sekedar memiliki prinsip dasar keimanan yang kuat tetapi juga dapat mewujudkan prinsip dasar moral dan etika sosial. Dalam kondisi semacam ini dasar keimanan yang kuat akan dapat mewujudkan kehidupan yang selaras dengan kehidupan sehari-hari seperti rasa keadilan sosial, keamanan, saling tolong menolong, menghormati, dan lainnya. ${ }^{1}$ Dakwah merupakan sesuatu kegiatan yang terpenting untuk mengatur kehidupan manusia, kapanpun, dan di manapun berada. Untuk itu isi pesan dakwah hendaknya mudah diterima, mudah dipahami, gagasan yang disampaikan dengan persuasif, dan mudah menggerakkan orang lain. Melalui cara demikian, dakwah akan dapat mewujudkan masyarakat pluralistik yaitu masyarakat yang memiliki sikap yang saling mengerti, memahami, dan menghormati adanya perbedaan-perbedaan demi terciptanya kerukunan antar ummat beragama. ${ }^{2}$

Kajian ini mencoba mengulas tentang hal tersebut dalam konteks sosiolinguistik. Penelitian ini merupakan hasil kajian awal terhadap buku AlMahfudzat karya KM. H. Syarifuddin Husain, M.HI. Sebagaimana diketahui, kajian terhadap peribahasa Arab di Indonesia memang masih sangat minim. Melalui buku ini, penulis berusaha mengkaji dan menulis berbagai hal terkait peribahasa Arab untuk memperkenalkannya kepada masyarakat Indonesia, terutama kepada para santri yang notabenenya mendalami ilmu agama termasuk 1992), h. 51.

${ }^{1}$ Nurcholish Madjid, Keislaman, Keindonesiaan dan Kemodernan, (Bandung: Mizan, 1972), h. 241.

W. Montgomery Watt., Muhammad at Madinah, (London, Oxford University Press, 
pembekalan dakwah sebagai calon mubalig. Olehnya itu, dengan melihat dari sisi sosiolinguistik dari peribahasa Arab dalam studi buku al-Mahfudzat Kelas IX MTs akan mengantarkan santri untuk lebih banyak pembekalan ilmu dalam mensyiarkan agama dalam bentuk metode dakwah.

\section{KAJIAN PUSTAKA}

Bahasa adalah alat komunikasi yang dipakai oleh masyarakat untuk mengekspresikan gagasan yang telah menjadi konsesus bersama. Ekspresi bahasa tersebut menggambarkan kecenderungan masyarakat penuturnya. Oleh karenanya, untuk mempelajari dan menjelaskan bahasa niscaya harus melibatkan aspek-aspek sosial yang mencitrakan masyarakat tersebut, seperti tatanan sosial, strata sosial, umur, lingkungan dan lain-lain. ${ }^{3}$ Berbeda dengan apa yang dikatakan oleh Chomsky bahwa bahasa adalah asosial karena mengabaikan heterogenitas yang ada dalam masyarakat, baik status sosial, pendidikan, umur, jenis kelamin latar belakang budayanya, dan lain-lain. ${ }^{4}$

Peranan bahasa yang utama adalah sebagai alat untuk berkomunikasi antara manusia yang satu dengan yang lain dalam suatu masyarakat. Hal tersebut sesuai dengan pendapat Mustakim bahwa bahasa sebagai alat komunikasi digunakan oleh anggota masyarakat untuk menjalin hubungan dengan masyarakat lain yang mempunyai kesamaan bahasa. ${ }^{5}$

Aspek pemakai bahasa berkaitan dengan mutu dan keterampilan berbahasa seseorang. Aspek pemakaian bahasa mengacu pada bidang-bidang kehidupan yang merupakan ranah pemakaian bahasa. ${ }^{6}$ Dalam menghadapi era globalisasi diperlukan suatu rumusan ketentuan mengenai penggunaan bahasa Indonesia. Hal ini mengingat bahwa masalah kebahasaan di Indonesia sangat rumit. Di Indonesia terdapat lebih dari 728 bahasa daerah. Bahasa-bahasa daerah itu hidup dan

\footnotetext{
${ }^{3}$ Harimurti Kridalaksana, Fungsi Bahasa dan Sikap Bahasa (Flores: Nusa Indah, 1985), h.. 4.

${ }^{4}$ Silal Arimi, "Sosiolinguistik" http://i-elisa.ugm.ac.id./ inex.php?app=komunitas_ home diakses pada 15 April 2008.

${ }^{5}$ Mustakim. 1994. Membina Kemampuan Berbahasa: Panduan ke Arah Kemahiran Berbahasa (Jakarta: PT Gramedia Pustaka Utama, 1994), h. 2.

${ }^{6}$ Hasan Alwi dan Dendy Sugono, Politik Bahasa (Risalah, 2000), h. 13.
} 
berkembang serta dipergunakan dengan setia oleh penuturnya. Selain itu, di Indonesia terdapat bahasa asing. Walaupun kedudukan dan fungsi bahasa daerah dan bahasa asing itu sudah diatur penggunaannya, tetap saja pemakaian bahasa daerah dan bahasa asing (Inggris) dipergunakan semaunya oleh pemakainya. Kenyataan itu akan menyudutkan penggunaan bahasa Indonesia. Seperti dikatakan oleh Hudson (1980) ragam bahasa itu bergantung pada who, what, when, where, why. Dengan demikian, dalam situasi formal tentulah ragam formal yang dipilih, sedangkan dalam situasi nonformal tentu pula ragam nonformal yang digunakan.

Untuk pemilihan ragam nonformal tidaklah perlu dipermasalahkan. Penggunaan bahasa Indonesia yang bercampur kode dengan bahasa gaul, prokem, slang, ataupun bahasa daerah selagi tidak tidak dipakai dalam situasi formal tidaklah perlu dirisaukan. Namun, yang menjadi kerisauan kalau ragam formal bahasa Indonesia (baku) itu digunakan tidak sebagaimana mestinya. Variasi atau ragam formal itu digunakan, antara lain, dalam pidato kenegaraan, rapat dinas, surat-menyurat dinas, ceramah keagamaan, buku pelajaran, karya ilmiah. ${ }^{7}$

Nilai-nilai dakwah harus diimplementasikan dalam kehidupan sehari-hari yang diajadikan landasan kuat untuk memberi arahan dalam mewujudkan kehidupan masyarakat yang pluralitas mengacu pada prinsip yaitu: (1) peradaban Islam berdiri atas landasan tauhid, (2) peradaban yang bersifat manusiawi, (3) selalu memegang prinsip moral, (4) percaya pada ilmu pengetahuan yang benar, dan (5) memiliki toleransi dalamberagama. ${ }^{8}$

Dalam Islam keluarga seyogyanya terjalin komunikasi yang baik, agar umpan balik yang diberikan anak kepada orang tua juga baik. Orang tua muslim tidak hanya memberikan informasi semata, tetapi hendaknya mengarahkan anggotanya menguasai berbagai kajian keislaman serta dapat mengamalkannya dalam kehidupan sehari- hari. Kondisi ini akan dapat menata dan membentuk perkembangan jiwa dengan baik, sehingga akan memiliki sikap dan perilaku religius yang baik. Orang tua adalah orang yang bertanggung jawab dalam suatu

\footnotetext{
${ }^{7}$ P.W.J. Nababan, Sosiolinguistik: Suatu Pengantar/P.W.J. Nababan (Jakarta: Gramedia Pustaka Utama, 1993).

${ }^{8}$ Mustofa al-Sibaeci, Rawai Hadaratina, (Beirut: Dar al-Irsyad, 1968), h. 29.
} 
keluarga atau rumah tangga yang biasa disebut ibu/bapak. ${ }^{9}$ Di samping itu pula akan tumbuh bibit-bibit generasi yang baik dan berkasih sayang yang memberikan kontribusi positif dalam kehidupan bermasyarakat dan bernegara. Islam mengajarkan pada ummatnya agar dapat membina dan membentuk keluarga sejahtera. Islam dalam ajarannya untuk dapat membentuk keluarga dan melestraikan kehidupan bersama yang bahagia oleh pasangan suami istri bersamasama anak-anak mereka. ${ }^{10}$

Menurut Fasold, pergeseran dan pemertahanan bahasa merupakan hasil dari proses pemilihan bahasa dalam jangka waktu yang sangat panjang. ${ }^{11}$ Pergeseran bahasa menunjukkan adanya suatu bahasa yang benar-benar ditinggalkan oleh komunitas penuturnya. Hal ini berarti bahwa ketika pergeseran bahasa terjadi, anggota suatu komunitas bahasa secara kolektif lebih memilih menggunakan bahasa baru daripada bahasa lama yang secara tradisional biasa dipakai. Sebaliknya, dalam pemertahan bahasa para penutur suatu komunitas bahasa secara kolektif memutuskan untuk terus menggunakan bahasa yang mereka miliki atau yang secara tradisional biasanya digunakan.

\section{METODE PENELITIAN}

Penelitian ini dilakukan dengan menggunakan metode kualitatif. Penelitian ini dilakukan dengan melakukan observasi ke lapangan secara langsung dengan teknik pengumpulan data melalui pengamatan dan pencatatan konteks suatu percakapan, merekam tuturan, dan wawancara. Setelah data tersebut terkumpul kemudian penulis mentraskripsi data lalu mengklasifikasi data berdasarakan domainnya. Setelah diklasifikasi, penulis melakukan analisis dengan menggunakan teori di atas dengan tujuan mencari gejala-gejala kebahasaan yang dapat menjadi indikator pergeseran atau pemertahanan bahasa, serta mencari faktor-faktor yang menyebabkan terjadinya pergeseran atau pemertahanan bahasa.

${ }^{9}$ Thamrin Nasution dan Nurhijah Nasution, Perana Orang Tua dalam Meningkatkan Prestasi Belajar Anak, (Yogyakarta: Kanisius, 1985), h. 1.

${ }^{10}$ Jalaluddin Rakhmat, Islam Aktual, (Bandung, PT Remaja Karya, 1992), h.40.

${ }^{11}$ Ralph Fasold, The Sociolinguistics of Society (England: Basil Blackwell Publisher, 1984), h. 213-214. 
Pendekatan sosiologi tampak pada analisis ranah sosial dalam pemakaian suatu kode, seperti ranah keluarga, ranah agama, dan ranah jualbeli. Meski begitu penelelitian ini tetap berada pada kajian sosiolinguistik yang lebih bertumpu pada permasalahan bahasa dalam hubungannya dengan masyarakat. ${ }^{12}$ Kajian sosiolinguistik melihat fenomena pemakaian bahasa sebagai fakta sosial yang menempatkan pemakaian suatu ragam bahasa sebagai sistem lambang (kode), sistem tingkah laku budaya, dan sistem pragmatik yang berhubungan dengan pemakian bahasa dalam konteks yang sebenarnya. Dengan demikian, kajian sosiolinguistik menyikapi fenomena pemilihan bahasa sebagai peristiwa komunikasi serta menunjukkan identitas sosial dan budaya peserta tutur. Oleh karena itu, pendekatan sosiolinguistik dalam kajian ini dipusatkan pada model etnografi komunikasi yang dikembangkan oleh Hymes. Pengembangan istilah itu dimaksudkan oleh Hymes untuk memfokuskan kerangka acuan karena pemberian tempat bahasa di dalam suatu kebudayaan bukan pada bahasa itu sendiri melainkan pada komunikasinya.

\section{HASIL PENELITIAN DAN PEMBAHASAN}

\section{Analisis Sosiolinguistik Teks Peribahasa Arab dalam Buku Al-Mahfudzat kelas IX MTs Karya Syarifuddin Husain Pesantren Modern Al-Junaidiyah Biru Bone.}

Berikut beberapa peribahasa Arab yang terdapat dalam buku Al-Mahfudzat Kelas IX MTs karya Syarifuddin Husain :

Kesopanan itu lebih berharga dari pada emas
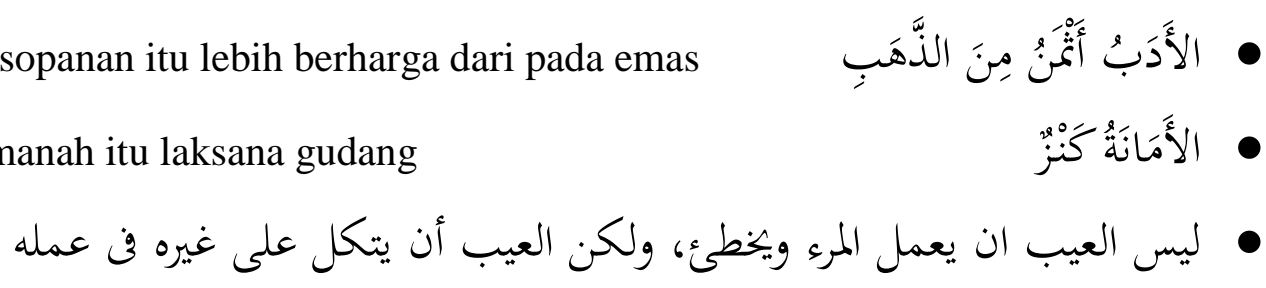

Bukanlah dinamakan aib apabila seseorang berbuat kemudian salah, tetapi aib itu adalah apabila seseorang bersandar kepada orang lain dalam

pekerjaannya

\footnotetext{
${ }^{12}$ Ronald Wardhaugh, An Intriduction to Lingusitics (New York: Basil, Blackwell, 1986), h.12.
} 
لا لا تصنع المعروف في غير أهله Janganlah berbuat kebaikan kepada orang yang

tidak berhak

إن مادح نفسة كذاب لا يصدق ولا يعتمد عليه Sesungguhnya orang yang memuji dirinya sendiri itu pembohong tidak jujur dan tidak dapat dipercaya

Apabila kemauan itu sungguh-sungguh, maka

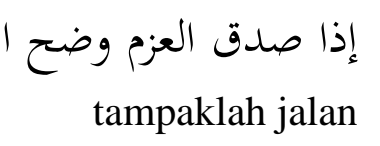

Dilihat dari berbagai kriteria klasifikasi sosiolinguistik bahasa,bahasa Arab yang terdapat di peribahasa Mahfudzatkelas IX MTs Karya Syarifuddin Husain Pesantren Modern Al-Junaidiyah Biru Bone termasuk variasi/ tipe bahasa Standar, dengan memenuhi ke 3 kriteria tersebut, yaitu standar, otonomi, dan historisitas. Standar, Bahasa Arab digunakan pada nomor 1 sampai 6 sebagai bahasa baku, baik dalam situasi formal dan informal, lisan maupun tulisan. Di Pesanten Modern Al-Junaidiyah ragam bahasa Arab Fusha(H) merupakan bahasa resmi dalam ranah keagamaan (multaqo, rauhah,maulid dan pertemuan kelompok besar klan Arab). Selain standar, kriteria lainnya adalah otonomi. Otonomi, Bahasa Arab digunakan pada nomor 1 sampai 6 memiliki kekhasan sendiri dan mempunyai suatu sistem, yaitu bahasa Arab tidak sama dengan bahasa yang lain. Bahasa Arab yang digunakan memiliki sistem tata-suara (Makhorijul Huruf), tata-kata (AsShorfu), dan tata bahasa (Nahwu) tersendiri. Seperti kalimat pada nomor 2 الأَمَانَةُ

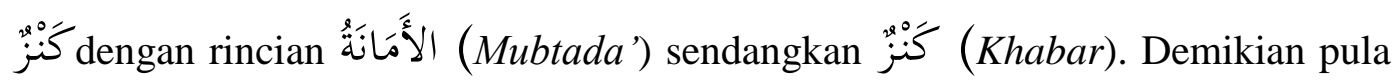
pada kalimat nomor ليس العيب ان يعمل المرء 3 ليس (Akhawatu Kana)(انعيب(Isim Kana), dan انعمل المرء (Jumlah Khabar Kana).

3) Historisitas 
Bahasa Arab ada sejak zaman dahulu. Salah satu bukti tertulismonumental adalah kitab suci umat Islam Al Qur'an ditulis denganmenggunakan bahasa Arab ragam tinggi (H/Fusha) dan teks-teks kunoyang berisi syair-syair susastra indah sebelum kelahiran NabiMuhammad. Bukti secara lisan, bangsa Arab terkenal dengan kekuatandaya ingat pikiran. Mereka selama ribuan tahun mampu menghafal kosakata, silsilah keluarga, karya sastra, bahkan ajaran-ajaran agama. Padabuku Mahfudzat yang peneliti kaji juga menggunakan bahasa Arab yang tertulismonumental secara historis 
Implementasi Nilai-nilai Dakwah Santri Pesantren Modern Al-Junaidiyah Biru Bone melalui Peribahasa Mahfudzat Kelas IX MTs.

Kegiatan dakwah yang dilakukan oleh Unit Intensifikasi Dakwah Pesantren Modern Al-Junaidiyah Biru dalam membina santri pada kehidupan pluralitas tidak menyalahi aturan atau undang-undang dalam agama maupun negara. Pembinaan itu harus sesuai dengan aturan pemahaman pluralisme dalam perspektif pembenaran keberagaman yaitu: a). Jangan sekali- kali memaksa. b). Masing-masing aliran memiliki nilai yang sama. c). Tidak ada kebenaran tunggal. d). Tidak satupun aliran yang bisa meniadakan aliran yanglainnya. ${ }^{13}$

Ahmad Genda menambahkan "bahwa dengan menggunakan peribahasa yang ada dalam buku mahfudzat tersebut dapat menambah dalil ketika santri membuat konsep dakwah yang tidak hanya bersumber dari al-Qur'an dan Hadits". ${ }^{14}$ Selanjutnya, A. Muhammad Fatih, salah satu santri MTs Kelas IX mengatakan : "Dalam kegiatan dakwah yang dilakukan setiap malam Senin beberapa santri menggunakan pepatah-pepatah Arab yang ada di buku mahfudzat selain menggunakan dalil Quran dan Hadits.”

Berikut Nilai-nilai dakwah santri Pesantren Modern Al-Junaidiyah Biru Bone melalui Peribahasa Mahfudzat kelas IX MTs.

a. Toleransi beragama.

Kesopanan itu lebih berharga dari pada emas

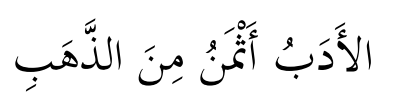

Kegiatan dakwah itu untuk membina keimanan dan mengembangkan hidup yang baik harmonis walaupun keberadaan mereka beda keyakinan, suku, adat, bahasa, etnis, dan lainnya atau hidup secara pluralitas. Kehidupan pluralitas masyarakat diharapkan tidak mengenal adanya perilaku pemilahan hubungan antara keanekaragaman manusia. Kesopanan merupakan salah satu sikap yang mampu menjalin hubnungan yang baik antar umat sesama manusa=ia terkhusus antar umat beragama. Keanekaragaman itu dapat mewujudkan adanya kehidupan yang

\footnotetext{
${ }^{13}$ Sulhan, Ketua Unit Intensifikasi Dakwah Pesantren Modern Al-Junaidiyah Biru, Hasil Wawancara,tanggal 2 Mei 2019.

${ }^{14}$ Ahmad Genda, Pembina Pesantren Modern Al-Junaidiyah Biru , Hasil Wawancara,tanggal 2 Mei 2019
} 
baik, sehingga tercipta persatuan, kesatuan, kedamaian, saling menghormat, dan saling menghargai, serta toleransi. Menurut bapak Mualim menjelaskan bahwa karakter adalah hal sangat urgen dalam menjadikan hubungan interaksi santri baik itu terhadap sesama teman maupun sesama guru dan orang tua.

\section{b.Kebersamaan.}

Kegiatan latihan dakwah santri Pesantren Modern Al-Junaidiyah Biru Bone adalah mengenai hidup kebersamaan. A. Ridwan, Lc menjelaskan bahwa dalam mencapai kemakmuran harus disertai usaha berjuang secara bersama. Tidak mengambil yang bukan haknya begitupun sebaliknya mendapatkan haknya yang sesuai. Salah satu peribahasa Arab yang berkaitan dengan hal itu adalah :

Janganlah berbuat kebaikan kepada orang yang tidak berhak. Lebih lanjut A. Ridwan menjelaskan bahwa saling memberikan hak kepada masing-masing yang dipahami hidup secara kebersamaan. Kebersamaan dalam kehidupan beranekaragam merupakan azas terpenting untuk memenuhi hajatnya, seperti keadilan, tidak ada kesewenang-wenang, tidak ada diskriminasi, tidak ada hidup terpecah belah, dan tercipta hidup dalam persatuan dan kesatuan. ${ }^{15}$

c. Berkeadilan.

Dimensi keadilan merupakan prasyarat mudahnya membina masyarakat yang dapat mencakup seluruh komponen masyarakat. Keadilan memiliki arti penting bagi masyarakat untuk memperkokoh ikatan dan menghilangkan fanatisme kesukuan. Keadilan merupakan tindakan sejajar dalam persesuaian warga pada hak-hak azasi dan kewajibannya. Melalui keadilan dapat diperhatikan prinsip-prinsip utama dalam hidup seperti: hak azasi, sistem hukum, dan diakuinya keberadaan dirinya, serta tidak adapenindasan.

Mengenai hal ini Ahmad Genda menghimbau pada setiap santri agar memperhatikan secara serius masalah keadilan. Keadilan dapat dikembangkan dalam pembagian secara proporsional, sehingga keadilan dapat ditegakkan sesuai

\footnotetext{
${ }^{15}$ A. Ridwan, Pembina Intensifikasi Dakwah Pesantren Modern Al-Junaidiyah Biru, Hasil Wawancara, Tanggal 5 Juni 2019.
} 
dengan peraturan yang berlaku. ${ }^{16}$ Salah satu peribahasa Arab yang berkaitan dengan hal tersebut adalah: الأَمَانَتُهُ كَنْزْ Amanah itu laksana gudang.

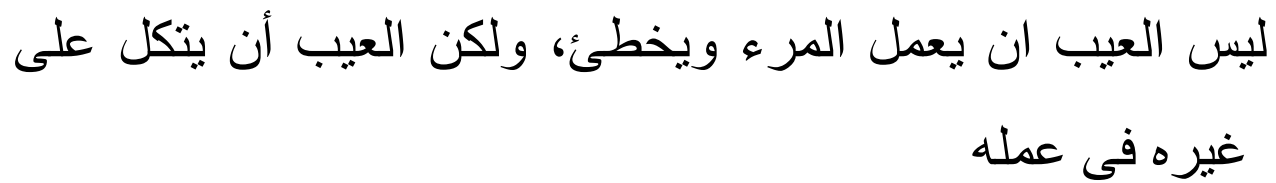

Bukanlah dinamakan aib apabila seseorang berbuat kemudian salah, tetapi aib itu adalah apabila seseorang bersandar kepada orang lain dalam pekerjaannya.

\section{PENUTUP/SIMPULAN}

Dari uraian yang telah penulis paparkan sebelumnya, maka dapat ditarik beberapa kesimpulan sebagai berikut:

1. Analisis Sosiolinguistik Teks Peribahasa Arab dalam Buku Al-Mahfudzat kelas IX MTs Karya SyarifuddinHusain Pesantren Modern Al-Junaidiyah Biru Bone terdapat tiga analisis diantaranya yaitu standar, otonom dan historitas. Standar adalah bahasa Arab digunakan pada nomor 1 sampai 6 sebagai bahasa baku, baik dalam situasi formal dan informal, lisan maupun tulisan. Di Pesanten Modern AlJunaidiyah ragam bahasa Arab Fusha $(\mathrm{H})$ merupakan bahasa resmi dalam ranah keagamaan (multaqo, rauhah, maulid dan pertemuan kelompok besar klan Arab). Selain standar, otonomi merupakan Bahasa Arab digunakan pada nomor 1 sampai 6 memiliki kekhasan sendiri dan mempunyai suatusistem, yaitu bahasa Arab tidak sama dengan bahasa yang lain. Selain itu, historisitas, bahasa Arab ada sejak zaman dahulu. Salah satu bukti tertulis monumental adalah kitab suci umat Islam Al Qur'an ditulis dengan menggunakan bahasa Arab ragam tinggi (H/Fusha) dan teks-teks kuno yang berisi syair-syair susastra indah sebelum kelahiran NabiMuhammad.

2. Implementasi Nilai-nilai Dakwah Santri Pesantren Modern Al-Junaidiyah Biru Bone melalui Peribahasa Mahfudzat kelas IX MTs terdapat tiga kategori nilai yaitu toleransi beragama, kebersamaan, dan berkeadilan.

\footnotetext{
${ }^{16}$ Ahmad Genda, Pembina Intensifikasi Dakwah Pesantren Modern Al-Junaidiyah Biru, Hasil Wawancara, Tanggal 2 Mei 2019.
} 


\section{DAFTAR PUSTAKA}

Fasold, Ralph.1984. The Sociolinguistics of Society. England: Basil Blackwell Publisher.

Hasan Alwi dan Sugono, Dendy. 2000. Politik Bahasa. Risalah

Hudson. R.A. 1980. Sociolinguistics. Cambridge: Cambridge

Kridalaksana, Harimurti. 1985. Fungsi Bahasa dan Sikap Bahasa. Flores: Nusa Indah.

Mustakim. 1994. Membina Kemampuan Berbahasa: Panduan ke ArahKemahiran Berbahasa. Jakarta: PT Gramedia Pustaka Utama.

Nababan, P.W.J. (1993) Sosiolinguistik: suatu pengantar/P.W.J. Nababan. Jakarta Gramedia Pustaka Utama 1993.

Penggunaan Bahasa." (http://www2,kompas. com.htm, diakses 10 September 2008.

Seminar Politik Bahasa. Jakarta: Pusat Bahasa. Chaer, A. \& Agustina, L. 1995. Sosiolinguistik Perkenalan Awal. Jakarta: Rineka Cipta.

Silal Arimi, "Sosiolinguistik" http://i-elisa.ugm.ac.id./ inex.php?app=komunitas home diakses pada 15 April 2008.

Susi Yuliawati. 2008 Situasi Kebahasaan di Wilayah Pangandaran: Suatu Kajian "Sosiolinguistik tentang Pergeseran dan Pemertahanan Bahasa". Makalah. Bandung: Fakultas Sastra Unpad University Press. Kompas, 22 Agustus 2005. "Mengatur

Wardhaugh, Ronald. 1986. An Introduction to Lingusitics. New York: Basil, Blackwell

Warsiman. 2007. Kaidah bahasa Indonesia yang Benar: untuk Penulisan Karya Ilmiah (Laporan-Skripsi-Tesis-Desertasi). Bandung: Dewa Ruchi.

Posted by Andri Wicaksono, M.Pd. at $\underline{04.22}$ 